\title{
Perspectivas da Educação Popular em Saúde e de seu Grupo Temático na Associação Brasileira de Saúde Coletiva (ABRASCO)
}

\author{
Perspectives of Popular Education in Health and its Thematic \\ Group at the Brazilian Association of Public Health (ABRASCO)
}

Luanda de Oliveira Lima (https://orcid.org/0000-0003-2764-0764) ${ }^{1}$

Maria Rocineide Ferreira da Silva (https://orcid.org/0000-0002-6086-6901) ${ }^{2}$

Pedro José Santos Carneiro Cruz (https://orcid.org/0000-0003-0610-3273) ${ }^{3}$

Renata Pekelman (https://orcid.org/0000-0002-6249-5542) ${ }^{4}$

Vanderleia Laodete Pulga (http://orcid.org/0000-0002-1918-0916) ${ }^{5}$

Vera Lúcia de Azevedo Dantas (https://orcid.org/0000-0002-3914-9078) ${ }^{6}$
${ }^{1}$ Programa de PósGraduação em Saúde Coletiva, Instituto Nacional de Saúde da Mulher, da Criança e do Adolescente Fernandes Figueira, Fundação Oswaldo Cruz. Av. Rui Barbosa 716, Flamengo. 22250-020 Rio de Janeiro RJ Brasil. luanda.ol@gmail.com ${ }^{2}$ Programa de PósGraduação em Saúde Coletiva, Universidade Estadual do Ceará. Fortaleza CE Brasil.

${ }^{3}$ Departamento de Promoção da Saúde, Centro de Ciências Médicas, Universidade Federal da Paraíba. João Pessoa PB Brasil.

${ }^{4}$ Curso de Medicina, Escola de Saúde, Universidade do

Vale do Sinos. São Leopoldo RS Brasil.

${ }^{5}$ Programa de Residência Multiprofissional em Saúde, Curso de Medicina Universidade Federal da Fronteira Sul. Passo Fundo RS Brasil.

${ }^{6}$ Secretaria Municipal de Saúde de Fortaleza. Fortaleza CE Brasil.

\begin{abstract}
Popular Education in Health (PEH) is a field of knowledge and practices permeated by listening, dialogue, and action. With a set of national experiences and productions, it is a political-pedagogical movement that articulates forces from various social and popular segments, health workers, educators, and researchers in collective health, among other actors. Supported by authors such as Paulo Freire and Victor Valla, among others, PEH has been strengthened in the dimensions of training, participation, management, and health care. Despite the dismantling experienced today in the Brazilian public scene, the PEH Thematic Group (TG) of the Brazilian Association of Public Health (ABRASCO) has been helping to foster, design, and express the voicing of the construction and development of participatory educational and democratic processes in Brazil. This paper showcases the experiences and elaborations of the TG members through the report of the collegiate coordination center members of the last administrations, a period of changes in the political, social, economic, educational and health scenarios, including the influence of the current planetary crisis brought about by the effects of COVID-19, especially in the Brazilian society.
\end{abstract}

Key words Popular education in health, Collective health, Community participation
Resumo A Educação Popular em Saúde (EPS) constitui um campo de conhecimentos, saberes e práticas, permeado pela escuta, pelo diálogo e pela ação. Com um conjunto de experiências e produções nacionais, é um movimento político-pedagógico que articula forças de vários segmentos sociais, populares, trabalhadores de saúde, educadores e pesquisadores da saúde coletiva, dentre outros atores. Sendo fundamentada por autores como Paulo Freire, Victor Valla, entre outros, a EPS vem sendo fortalecida nas dimensões da formação, da participação, da gestão e do cuidado em saúde. O Grupo Temático (GT) de EPS da Associação Brasileira de Saúde Coletiva (ABRASCO) vem ajudando a fomentar, desenhar e expressar, apesar do desmonte vivido nos tempos de hoje na cena pública brasileira, processos de vocalizações da construção e desenvolvimento de processos educativos participativos e democráticos no Brasil. O presente artigo apresenta as experimentações e elaborações dos membros do GT através do relato dos componentes do núcleo de coordenação colegiada das últimas gestões, período reconhecido de mudanças nos cenários políticos, sociais, econômicos, educativos, sanitários, incluindo a influência da atual crise planetária que vivemos, pelos efeitos da COVID-19, especialmente na sociedade brasileira.

Palavras-chave Educação popular em saúde, Saúde coletiva, Participação comunitária 


\section{Introdução}

A saúde da(s) coletividade(s) precisa(m) ser escutada(s). Esta que transita entre o singular e o plural, não apenas na perspectiva morfológica, mas também com todas as dimensões compatíveis com a vida na diversidade de territórios em que sujeitos estão inseridos. Tem sido a partir do encontro entre práticas de educação popular com a saúde que, no Brasil, podemos afirmar que se constituiu o campo da Educação Popular em Saúde (EPS), permeado de escuta/diálogo e ação, onde um movimento político-pedagógico emerge alicerçado pela articulação entre forças de vários segmentos sociais, populares, trabalhadores(as) e profissionais de saúde, educadores(as) e pesquisadores(as) do campo da saúde coletiva, estudantes de diversas áreas da saúde, dentre outros atores.

Paulo Freire ${ }^{1}$ fala-nos da importância de reconhecer o saber de experiência feito. E também Victor Valla ${ }^{2}$, referência acadêmica no campo, já nos chamava atenção sobre o quanto escutar e as representações de se escutar podem ter materialidades diferentes a depender da posição do falante e do escutador.

O Grupo Temático (GT) de EPS da Associação Brasileira de Saúde Coletiva (ABRASCO) tem assumido os princípios freireanos, hoje também reconhecidos como princípios da Política Nacional de Educação Popular em Saúde no Sistema Único de Saúde (PNEPS-SUS), que seus membros ajudaram a fomentar, desenhar e expressar ${ }^{3}$. Apesar do desmonte vivido nos tempos de hoje na cena pública brasileira, a EPS permite que vocalizações sejam escutadas, diálogos estabelecidos, e, assim, possamos dizer que a construção e desenvolvimento de processos educativos participativos e democráticos sejam vislumbrados, inclusive pela apropriação na extensão e na pesquisa de abordagens pedagógicas capazes de promover interação comunitária, social e popular.

O presente artigo visa relatar as experimentações dos membros do GT de EPS através do relato dos componentes do núcleo de coordenação colegiadas das últimas gestões, período reconhecido de mudanças nos cenários políticos, sociais, econômicos, educativos e sanitários do próprio GT. O artigo sofre ainda influência da atual crise planetária que vivemos nesse momento, pelos efeitos do Coronavirus Disease (COVID-19), especialmente na sociedade brasileira. Nesse contexto, a partilha do vivido em tantos outros lugares por tantos outros povos já se apresenta com trilhas potentes para seguir.

\section{As principais ações do GT no período 2016/2020}

É importante destacar que a condução metodológica nos termos da educação popular constituiu uma das principais preocupações dos procedimentos organizativos no transcorrer da última gestão do núcleo de coordenação do GT de EPS da ABRASCO. Desde 2016, buscou-se orientar a forma de conduzir os processos internos ao GT, bem como as relações entre os seus sujeitos participantes e a mediação em diferentes frentes de trabalho, por caminhos que estivessem encharcados de elementos como o diálogo e a participação. Dentre outros procedimentos próprios dessa forma de mediar o Grupo, priorizou-se, desde o início desse ciclo, constituir o GT como uma comunidade de trabalho. O conceito de comunidade de trabalho foi proposto por Oliveira ${ }^{4} \mathrm{e}$ outros autores a partir de estudos e pesquisas no âmbito da Universidade Federal de São Carlos. Uma comunidade de trabalho, nas palavras de Silva e Araújo-Oliveira": "se constitui em torno de objetivos comuns que ultrapassam a ordem do pessoal, se situam e enraízam em compromisso com a construção de uma sociedade justa que garanta iguais direitos e tratamento diverso para diferentes condições, circunstâncias, oportunidades sócio-histórico-sociais".

Essa comunidade é mediatizada, em suas relações e ações, pelo trabalho. Assim, é também uma rede voltada ao desvelamento de uma ação transformadora, que é potencializada por frentes de trabalho constituídas por sujeitos com diferentes perfis e potências, mas que atuam na perspectiva de uma complementaridade, pela união cooperativa e solidária das pessoas, de forma amorosa, solidária e dialógica, de modo que essa comunidade consegue chegar muito mais longe no alcance dos objetivos, principalmente aqueles coletivamente pactuados.

Nessa direção, além de construir um ambiente no qual as pessoas se compreendessem como membros de uma comunidade, uma das providências do núcleo gestor foi construir coletivamente frentes de ação nas quais os membros poderiam e deveriam se inserir, participar e contribuir. Seus protagonistas, vindos cada um de diferentes experiências, poderiam e deveriam juntar-se para identificar os desafios do campo EPS e da área da Saúde Coletiva, constituindo uma comunidade compromissada e empenhada em pensar esforços visando à superação desses desafios, através da contribuição criativa, criadora e transformadora da atividade social, da pes- 
quisa socialmente referenciada e dos processos formativos.

É importante destacar que esse caminho de constituição do GT permitiu que se vislumbrasse um fio condutor do coletivo, com o qual se passou a pautar as reuniões sistemáticas da equipe, as quais, também nesse período, aumentaram significativamente em frequência e regularidade, graças à possibilidade de realização de reuniões virtuais.

Uma das principais frentes de ação nas quais o GT se dedicou nos últimos anos foi o apoio sistemático a publicações no campo da EPS. Essa frente teve como objetivo a possibilidade de que as experiências de EPS pudessem ser cada vez mais partilhadas e socializadas com um público cada vez maior e mais diversificado.

A concepção da educação popular vem contribuindo com a reorientação de diversas políticas públicas e com a construção de práticas sociais potentes que conseguem lograr êxito na constituição de experiências e práticas concretas em diversos territórios, desde a atenção básica até a atenção terciária à saúde, na construção de um agir em saúde que seja crítico, humanizado, participativo e inclusivo. Dessa forma, o GT dedicou-se à mobilização de diferentes oportunidades para que as experiências de educação popular realizadas em todo o território nacional tivessem espaço para a explicitação dos conhecimentos, metodologias, saberes, ideias e práticas nelas produzidos.

Tendo como ponto de partida esse olhar, nos últimos anos, foram abertas possibilidades de publicação em três Dossiês Temáticos em parceria com revistas científicas como a Interface - Educação, Comunicação e Saúde, da Universidade Estadual de São Paulo, Campus Botucatu; além de organização de dois e-books: "Educação Popular em Saúde" e "Participação Social em Saúde", pela Editora do Centro de Comunicação, Turismo e Artes (CCTA), da Universidade Federal da Paraíba (UFPB), no prelo; e de dois livros: "Educação Popular em Saúde: desafios atuais" e "Agir crítico em Saúde", pela Hucitec Editora, o primeiro publicado em 2018, e o segundo no prelo.

Outra frente de ação de destaque no âmbito do GT nos últimos anos consistiu da construção compartilhada de um projeto de pesquisa em EPS de cunho nacional, promovido através da articulação multicêntrica de diferentes universidades e instituições de ensino representadas pelos diferentes membros do GT, mas coordenada pela Universidade do Estado do Rio de Janeiro (UERJ). A principal intenção desse projeto de pesquisa es- tava em dar visibilidade às experiências do campo promovidas em todo o país, na perspectiva de situá-las, identificá-las, caracterizá-las e descrevê -las, para que, assim, pudéssemos ter um levantamento que explicitasse o desenvolvimento da EPS nos vários serviços de saúde no Brasil, bem como nas instituições de ensino e, particularmente, mas com destaque, junto aos movimentos sociais e as práticas populares. Dentro do contexto dessa atividade, destacou-se, em um primeiro momento, um subprojeto dedicado ao desvelamento do que chamamos de uma "Antologia da EPS Brasileira". Esse subprojeto consiste na possibilidade de se realizarem entrevistas orientadas pela perspectiva da história de vida, com atores e atrizes que construíram historicamente a EPS no país, de forma que a sua memória e o seu olhar histórico sejam registrados, com ênfase em sua trajetória e em suas experiências, bem como em suas impressões e considerações sobre o atual contexto e os seus desafios para o campo.

Outra frente de ação importante do GT constituiu da promoção de espaços e contextos de compartilhamento de experiências, bem como de organização política do movimento de EPS. Nessa perspectiva, coube ao GT propor a criação de espaços públicos onde a EPS fosse discutida a partir do compartilhamento de experiências e diálogo dos seus protagonistas, de modo a aprenderem e fazerem processos de ensino e aprendizagem uns com as experiências dos outros. Em tais espaços, abriram-se momentos de discussão sobre a educação popular e sua interface com a conjuntura atual brasileira. Isso se deu de modo especial a partir de 2016, período no qual se acentuaram ataques à democracia, aos direitos sociais e humanos e às políticas sociais inclusivas e participativas.

Destaca-se o apoio do GT, juntamente com vários de seus protagonistas, em diferentes conferências de saúde em todo o território nacional durante o ano de 2019, que foi um ano difícil do ponto de vista da participação nas políticas públicas, tendo em vista as crescentes ameaças à democracia, as retiradas de direitos e a extinção de espaços participativos no âmbito da República Brasileira. Nas conferências, os membros do GT atuaram para mobilizar protagonistas da sociedade a participarem de forma insistente, propositiva e crítica das conferências tanto municipais e estaduais, como a promoção da Conferência Livre Nacional de EPS, realizada em final de maio de 2019, no município de Passo Fundo, no estado do Rio Grande do Sul, e a participação ativa na $16^{a}$ Conferência Nacional de EPS, com 
várias ações na Tenda Paulo Freire, nos espaços de cuidado e nas comissões, em agosto de 2019, em Brasília, no Distrito Federal.

O GT realizou, em parceria com a Universidade Estadual do Ceará, o I Seminário Temático, no ano de 2018, atividade preparatória do 12 Congresso Brasileiro de Saúde Coletiva, que teve como questão central a participação popular e seus desafios no âmbito do SUS. Outro evento importante realizado foi o II Seminário Temático do GT, realizado em Parnaíba, no Piauí, na Universidade Federal do Delta do Parnaíba, no qual foram promovidos debates aprofundados sobre diferentes questões emergentes no campo da educação popular, que foram sendo desveladas no decorrer da última gestão do GT, como a EPS e suas interfaces com a produção do conhecimento, a pesquisa, a formação em saúde, a participação social em saúde, as artes e as múltiplas linguagens, dentre outras.

Finalmente, no que tange aos espaços de encontro, destaca-se a realização do VI Encontro Nacional de EPS (ENEPS), que cumpriu o papel de, mais uma vez, proporcionar a reunião do movimento de educação popular brasileiro com seus vários coletivos, seus vários grupos, suas várias práticas e experiências. O ENEPS é um espaço para mediatização do diálogo das práticas e dos coletivos nacionais de EPS.

Afirmando a EPS como ambiente de resistência, de construção de possibilidades e de defesa do SUS, o VI ENEPS teve como tema os "Caminhos para a democracia, a autonomia e o Bem viver". Buscando construir um espaço acolhedor que promovesse o diálogo e a troca entre todos, o encontro foi majoritariamente realizado em rodas de conversa e de diálogo, com questões disparadoras apresentadas por pessoas convidadas ou pelos apresentadores de trabalhos, que inscreveram previamente suas vivências e pesquisas. Como encaminhamento, a plenária do Encontro pactuou que é preciso que os movimentos e atores se articulem e atuem de formas conjuntas em ações locais, fomentando a EPS nas formas diversas de construir saúde. A comunicação entre os que constroem a EPS também foi ressaltada pela importância de realizar ações articuladas e de compartilhar as que estão sendo realizadas nos diversos espaços pelo país.

Durante o VI ENEPS, ocorreu a transição do núcleo colegiado de coordenação do GT. Com a ampliação do campo da educação popular na saúde e seu fortalecimento epistêmico, seja no âmbito de produções e reflexões teóricas ou no campo das experiências, um número cada vez maior de trabalhadores e pesquisadores passaram a construir suas práticas com essa perspectiva. Esse crescimento, com atuação proativa dos membros do GT na construção da PNEPS-SUS e reconhecimento por parte da Saúde Coletiva, levou vários pesquisadores a se interessarem em compor esse grupo. Diante disso, nos últimos dois anos, o grupo gestor promoveu discussões dentro do GT em relação a critérios de participação, considerando a perspectiva de, de fato, constituirmo-nos como uma comunidade de trabalho. Esses critérios foram amadurecidos pelo coletivo, com um aprofundamento sobre o que esperamos produzir como GT, por quais caminhos e que compromisso com este coletivo podemos esperar de seus membros. Nesse processo, algumas companheiras e companheiros nos deixaram, e outros agregaram-se, pois temos este caminho em comum.

É importante considerar que se estabeleceu no GT que os lugares de coordenação precisam ser transitórios, pois todos os participantes estão aptos a assumi-los, e a alternância no lugar de liderança é um critério ético central para a condução política do Grupo. Optamos por realizar um processo bastante dialogado de transição, mantendo um núcleo gestor colegiado com o máximo de representação regional e com variedade na representatividade geracional. O Grupo entende como fundamental esse processo de transição, para que o trabalho realizado até o momento siga dando centralidade para o GT e a EPS.

Por sua vez, a realização do I Colóquio Internacional de EPS, realizado em março de 2020, em Passo Fundo, foi um momento marcante de debates, aprofundamento e visibilidade das diferentes dimensões da EPS, com a participação ativa de vários integrantes deste GT da ABRASCO e de mais de 700 protagonistas de todas as regiões do Brasil, além de representantes de países como Itália, Bolívia, Argentina, República Tcheca e Eslováquia.

Buscando manter os mesmos caminhos éticos e metodológicos da gestão anterior, uma série de ações e discussões vêm sendo articuladas e promovidas ao longo do último ano pelo GT. Algumas dão continuidade às da gestão anterior, e outras têm sido construídas, especialmente em face ao contexto da pandemia de COVID-19. Com o isolamento e o distanciamento físicos, tivemos todos que reinventar a nós mesmos e a nossas formas de agir no mundo, de incidir na sociedade, repensando nossas formas de fazer.

Nos últimos meses, o GT vem realizando reuniões em periodicidade quinzenal, a fim de 
refletir sobre as possibilidades de construir EPS, nesse atual contexto, em algumas situações com os limites de contato físico, que agrega elementos tão caros à perspectiva popular de empatia $e$ amorosidade, como o abraço, o toque e o olhar.

Dessa forma, mediante a necessidade de isolamento social, temos refletido acerca da urgência de repensarmos as nossas presencialidades e construir espaços polifônicos de comunhão entre os saberes, permitindo sua expressão através de múltiplas possibilidades criativo-inventivas; de ensinar e aprender, refletir e agir com e sobre o mundo. Para isso, temos buscado nos encontrar mais, mesmo que virtualmente, para trocar sobre nossa experiência. Estamos, também, organizando materiais e espaços abertos que tragam outro olhar para o cuidado, além do higienista-sanitário, que valorize os diversos locais de fala, as múltiplas experiências e saberes.

Os desafios impostos pela pandemia do COVID-19 revelam a necessidade de ampliação e de aprofundamento das práticas de EPS, seja para envidar esforços de formação crítica dos trabalhadores de saúde e dos demais atores sociais na área (como os grupos e os movimentos sociais populares), seja para a criação, a recriação e o aprimoramento de espaços sociais e comunitários nos territórios para o apoio solidário e para o estabelecimento de relações de reciprocidade em um momento de exigentes e complexas demandas do ponto de vista emocional. Outra frente importante é pautar a EPS como referencial em processos de mediação na luta pelos direitos dos trabalhadores de saúde em tempos de pandemia, incluindo-se aqueles em contextos hospitalares e os agentes comunitários de saúde, e também para a qualificação da luta social da população pelo direito à saúde, incluindo-se o acesso ao sistema de saúde em casos de urgência em decorrência do novo coronavírus. Finalmente, pensar a EPS na orientação de trabalhos sociais voltados ao enfrentamento da pobreza econômica e dos processos de exclusão social que, certamente, passam a ser intensificados, tanto pela crise sanitária em curso, como pelas necropolíticas de um governo que, pautado pelo ultraliberalismo e pelo ultraconservadorismo, estabelece uma agenda pública de barbárie e de esgarçamento do tecido social, sobretudo das classes populares.

\section{Conclusões}

Diante das reflexões trazidas sobre as perspectivas atuais da EPS a partir das experiências do GT de EPS da ABRASCO e dos desafios da realidade, podemos caracterizar as perspectivas em alguns movimentos articulados no sentido de atuar no:

a. Fortalecimento das lutas por democracia, afirmação de direitos, de fortalecimento do SUS, de Políticas Públicas e do Projeto Democrático e Popular com base no Bem Viver e na defesa da vida no Planeta, como elementos norteadores do agir das pessoas engajadas no GT e da sua articulação com entidades, organizações, associações científicas e movimentos sociais populares;

b. Aprimoramento das práticas educativas baseadas na EPS, tanto nos espaços formais como informais; nas pesquisas, em programas e projetos de extensão popular e em interações comunitárias e com movimentos sociais populares; assim como em ações de práticas populares e integrativas de cuidado em saúde e de saúde e arte;

c. Processo de construção teórica das bases que fundamentam o agir crítico e libertador produzido pelas práticas de EPS;

d. Caminho de construção de ações articuladas em redes colaborativas e solidárias nacionais e internacionais de educação popular e saúde; de participação e controle social;

e. Compromisso de atuação em defesa da Saúde em Defesa da Vida, onde todas as vidas valem.

\section{Colaboradores}

Todos(as) os(as) autores(as) participaram da concepção e delineamento ou análise e interpretação dos dados, redação do artigo ou da sua revisão crítica, e aprovação da versão a ser publicada. 


\section{Referências}

1. Freire P. Pedagogia do oprimido. Rio de Janeiro: Paz e Terra; 2005.

2. Valla VV. A crise da interpretação é nossa: procurando entender a fala das classes subalternas. In: Brasil. Ministério da Saúde (MS). Secretaria de Gestão Estratégica e Participativa. Departamento de Apoio à Gestão Participativa. II caderno de educação popular em saúde. Brasília: MS; 2014. p. 35-48.

3. Brasil. Ministério da Saúde (MS). Secretaria de Gestão Estratégica e Participativa. Politica Nacional de Educação Popular em Saúde (PNEPS-SUS). Brasília: MS; 2012.

4. Oliveira MW. Pesquisa e trabalho profissional como espaços e processos de humanização e de comunhão criadora. Cad Cedes 2009; 29(79):309-321.

5. Silva PBG, Araújo-Oliveira SS. Cidadania, ética e diversidade: desafios para a formação em pesquisa. In: Actas del VI Encuentro del Corredor de las Ideas del Cono Sur. Montevideo; 2004. p. 1-8.

Artigo apresentado em 22/05/2020

Aprovado em 22/05/2020

Versão final apresentada em 24/05/2020 